\title{
Rapid, Plateau-like Increases in Intracellular Free Calcium Are Associated with Nod-Factor-Induced Root-Hair Deformation
}

\author{
Christoph A. Gehring, ${ }^{1,5}$ Helen R. Irving, ${ }^{3}$ Akram A. Kabbara, ${ }^{2}$ Roger W. Parish, ${ }^{1}$ Nawal M. Boukli, ${ }^{4}$ \\ and William J. Broughton ${ }^{4}$ \\ ${ }^{1}$ School of Botany and ${ }^{2}$ School of Zoology, La Trobe University, Melbourne Victoria 3083, Australia; \\ ${ }^{3}$ Department of Pharmaceutical Biology \& Pharmacology, Victorian College of Pharmacy, Monash Uni- \\ versity, Parkville Campus, 381 Royal Parade, Melbourne Victoria 3052, Australia; ${ }^{2}$ Laboratoire de Biolo- \\ gie Moléculaire des Plantes Supérieures, Université de Genève, 1 chemin de l'Impératrice, 1292 Cham- \\ bésy-Genève, Switzerland; ${ }^{5}$ New address: School of Biological \& Chemical Sciences, Deakin University, \\ Geelong campus, Geelong, Victoria 3217, Australia \\ Received 19 May 1997. Accepted 7 July 1997.
}

Rhizobia excrete variously substituted lipo-oligosaccharide Nod factors into the legume rhizosphere. Homologous legumes respond to these signals through deformation of the root hairs and the development of nodulation foci in the root cortex. Cellular events in root hairs from the susceptible zone of nearly mature root hairs were studied in root segments loaded with the calcium indicators Fura-2 or Fluo-3. Application of $10^{-9} \mathrm{M}$ Nod factors of the broadhost-range Rhizobium sp. NGR234 to the homologous legume Vigna unguiculata resulted, within seconds, in plateau-like increases in intracellular free calcium $\left(\left[\mathrm{Ca}^{2+}\right]_{i}\right)$ in root hairs and root epidermal cells. Nod factors of $R$. meliloti at $10^{-9} \mathrm{M}$ caused equally rapid increases in $\left[\mathrm{Ca}^{2+}\right]_{\mathrm{i}}$ in the root hairs and epidermal cells of the nonhost $V$. unguiculata, and also induced root-hair deformation. The chitin tetramer, $N-N^{\prime}-N^{\prime \prime}-N^{\prime \prime \prime}$-tetracetylchitotetraose, which represents the backbone of Nod factors, induced neither root-hair deformation nor changes in $\left[\mathrm{Ca}^{2+}\right]_{i}$ in $\mathrm{V}$. unguiculata. Root hairs and epidermal cells of the nonlegume nonhost Arabidopsis thaliana showed neither $\left[\mathrm{Ca}^{2+}\right]_{\mathrm{i}}$ increases nor root-hair deformation in response to both factors.

Soil bacteria of the genera Azorhizobium, Bradyrhizobium, Rhizobium, and Sinorhizobium (collectively referred to as rhizobia) interact with the roots of legumes to form nodules in which atmospheric nitrogen may be fixed. Rhizobia in the rhizosphere bind to receptive root hairs of host plants. In effective associations, the bacteria then provoke deformation (Had) followed by curling (Hac) of the root hairs and formation of the infection thread (for reviews see Brewin 1991; Fellay et al. 1995; Fisher and Long 1992; Hirsch 1992; Mylona et al. 1995). At this stage, cortical cells are mitotically activated to form nodule primordia. Rhizobia invade the plant by traveling

Corresponding author: William Broughton; Telephone: (41) 90617 40; Fax: (41) 2290617 41, E-mail: brought2@sc2a.unige.ch

The first two authors contributed equally to this project. along the infection thread that grows toward the primordium. Within the root, the rhizobia become encased in the peribacteroid membrane and are released into the cytoplasm of the cortical cells. Cortical cells and bacteria continue to differentiate, culminating in nitrogen-fixing nodules (Brewin 1991; Mylona et al. 1995).

Symbiotic interactions begin in response to flavonoids released from legume roots that are recognized by constitutively expressed NodD proteins. Flavonoid-NodD complexes form one level of specificity as rhizobial NodD proteins vary in their ability to interact with flavonoids of different plants (Brewin 1991; Hirsch 1992; Fellay et al. 1995). Binding of flavonoids to the NodD proteins results in expression of nodD-dependent nod genes that encode enzymes involved in the synthesis and excretion of Nod factors (Brewin 1991; Dénarié and Cullimore 1993; Fisher and Long 1992; Hirsch 1992; Mylona et al. 1995). Nod-factors are $N$-acylated oligomers of $\beta$-1,4-linked $N$-acetyl-D-glucosamine (three to six subunits) with various substitutions on the terminal sugar

Table 1. Ability of Rhizobium sp. NGR234 and R. meliloti RCR2011 to nodulate, and of their respective Nod factors to induce root-hair deformation on Vigna unguiculata

\begin{tabular}{lcccc}
\hline & & \multicolumn{3}{c}{ Root-hair deformation $^{\mathbf{c}}$} \\
\cline { 3 - 5 } Rhizobium & $\begin{array}{c}\text { Nodu- } \\
\text { lation }^{\mathbf{a}}\end{array}$ & Nod factor $^{\mathbf{b}}$ & $\begin{array}{c}\text { Intact } \\
\text { plant }\end{array}$ & $\begin{array}{c}\text { Root } \\
\text { segments }\end{array}$ \\
\hline $\begin{array}{c}\text { Rhizobium } \mathrm{sp} . \\
\text { NGR234 }\end{array}$ & Fix $^{+}$ & NodNGR[Ac,S] & Had, Hac & Had, Hac \\
$\begin{array}{c}\text { R. meliloti } \\
\text { RCR2011 }\end{array}$ & Nod $^{-}$ & NodRmIV,V[Ac,S] & Had & NT \\
& & TACT & Nor & NT \\
\hline
\end{tabular}

${ }^{a}$ Tests for nodulation were performed in Magenta jars under standard conditions (Lewin et al. 1990). Phenotypes: Nod $^{-}$, rhizobia unable to nodulate; Fix ${ }^{+}$, rhizobia nodulate and fix nitrogen; NT, not tested.

${ }^{\mathrm{b}}$ Nod factors and TACT were tested at $10^{-9}$ and $10^{-7} \mathrm{M}$, respectively. TACT is $N-N^{\prime}-N^{\prime \prime}-N^{\prime \prime \prime}$-tetracetylchitotetraose, which represents the Nod-factor backbone.

c Tests for root-hair deformation were performed as described by Price et al. (1992). Phenotypes: Had, root-hair deformation; Hac, root-hair curling; Nor, no apparent root-hair deformation. 


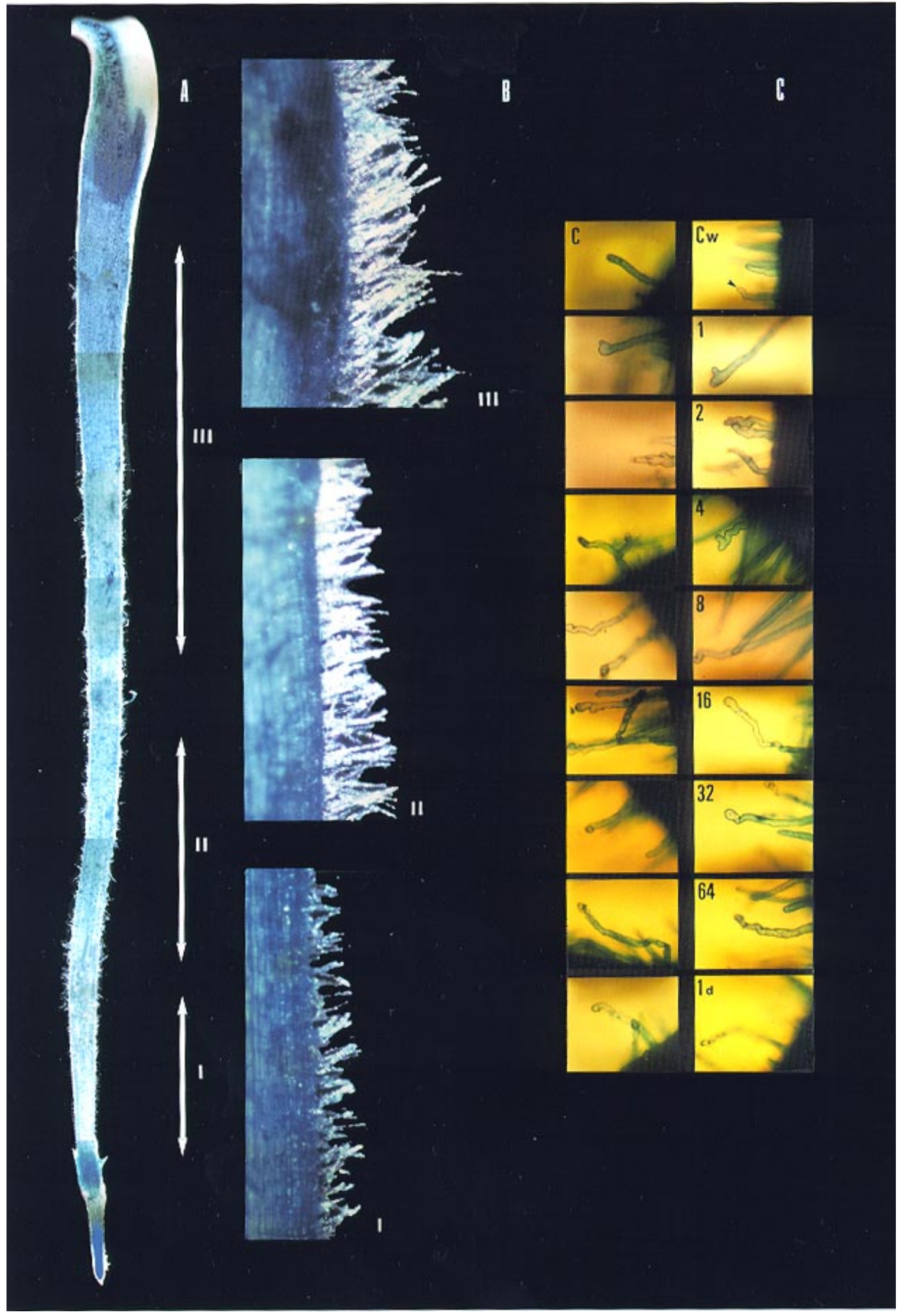


Fig. 1. Root zones, and effect of NodNGR factors on root-hair deformation of intact Vigna unguiculata seedlings. A, Complete nontreated root system of a 2-day-old V. unguicalata seedling. B, Enlarged portions of a V. unguiculata root treated with $10^{-9} \mathrm{M} \mathrm{NodNGR[Ac,S],} \mathrm{showing} \mathrm{immature} \mathrm{(bottom),}$ newly mature (middle), and mature (top) root-hairs. Zones are labeled I, II, and III, respectively, to be consistent with Heidstra et al. (1994). C, Types of deformation of $V$. unguiculata root hairs provoked by in planta treatment with $10^{-9}$ M NodNGR[Ac,S] factors. Numbers $=$ minutes of exposure to Nod factors except for bottom row, which is in days. Two photos, representative of types of deformation, are shown for each time. After exposure, Nod factors were "washed out" with a 10,000-fold excess of B \& D solution, and the seedlings allowed to grow for a further 16 h. C: control; CW: control washed. Arrow shows deformation caused by washing (see Materials and Methods).

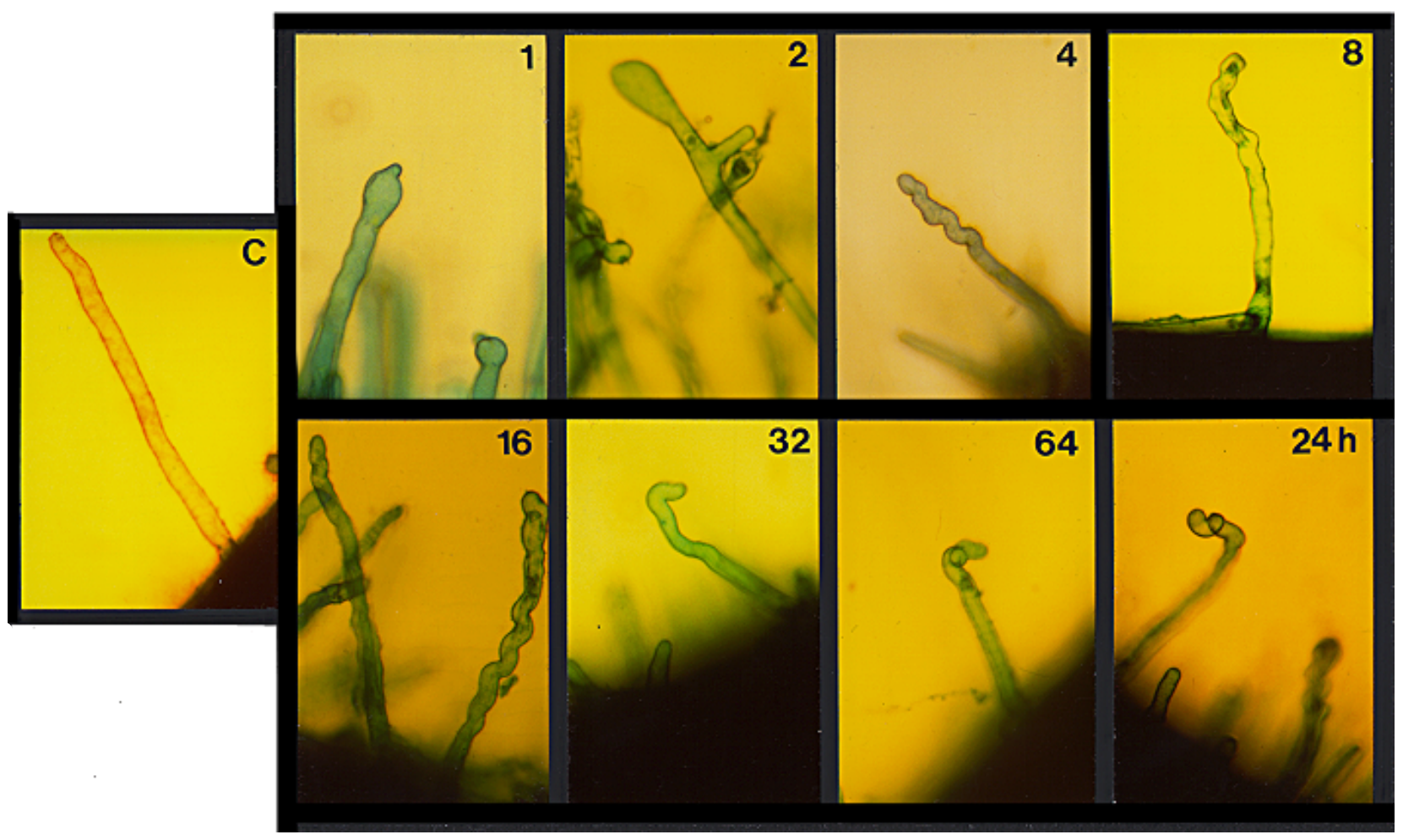

Fig. 2. Effect of $10^{-9} \mathrm{M}$ NodNGR[Ac,S] on root-hair deformation of the "newly mature" zone II, which was excised from Vigna unguiculata roots (see Materials and Methods). Numbers represent minutes of exposure to Nod factors except for 24, which is in hours. C: control.

residues (Dénarié and Cullimore 1993). Purified Nod factors provoke Had and occasionally Hac in homologous legumes (van Brussel et al. 1992; Heidstra et al. 1994; Kurkdjian 1995; Lerouge et al. 1990; Mergaert et al. 1993; Mylona et al. 1995; Price et al. 1992; Spaink et al. 1991). Specific plant genes are induced, followed by organized cell divisions in the root cortex that can, in some host plants, result in non-nitrogen-fixing nodules (Cook et al. 1995; Journet et al. 1994; Mergaert et al. 1993; Mylona et al. 1995; Relić et al. 1994; Truchet et al. 1991). Various substitutions and the length of the Nod-factor backbone form another level of specificity in rhizobia-host interactions (Dénarié and Cullimore 1993; Mylona et al. 1995). The fatty acyl group is required at the nonreducing terminus for induction of Had and expression of specifically induced epidermal genes (Heidstra et al. 1994; Journet et al. 1994; Mylona et al. 1995). Sulfur substitutions on the reducing terminus can also be major determinants of the ability to induce Had in susceptible species while the activation of cortical cells is even more dependent on specific structures (Ardourel et al. 1994; Heidstra et al. 1994; Mylona et al. 1995; Roche et al. 1991).

How Nod factors induce these changes is unclear, although recognition of Nod factors by the plant is evidently important. Both Had and Hac involve modifications of the growth of root hairs. Root hairs are tubular extensions of epidermal cells with the growing region in the apical dome of the hair (Aeschbacher et al. 1994). Root hairs just prior to maturity are most susceptible to Nod factors (Heidstra et al. 1994; Hirsch 1992; Kurkdjian 1995). With micro-electrodes, it has been shown that only Had-competent root hairs consistently respond to $R$. meliloti Nod factors with a concentration-dependent and rapid membrane potential depolarization (Ehrhardt et al. 1992; Felle et al. 1995; Kurkdjian 1995). It has been suggested that the ionic re-distribution leading to this membrane potential depolarization might accompany a cellular signal event or play a mechanistic role in nodulation (Ehrhardt et al. 1992). Roothair length is dependent upon external $\mathrm{Ca}^{2+}$ levels (Cormack 1949), which is reflected in a $\mathrm{Ca}^{2+}$ gradient toward the tip where a net influx of $\mathrm{Ca}^{2+}$ occurs (Allen et al. 1994; Clarkson et al. 1988; Schiefelbein et al. 1992). Vibrating microelectrode measurements indicate that the $\mathrm{Ca}^{2+}$ influx at the tip is absent from mature or nongrowing root hairs (Allen et al. 1994; Schiefelbein et al. 1992). Since $\mathrm{Ca}^{2+}$ is involved in regulation of cytoskeletal development (Bush 1995; Jackson 
and Heath 1993) and cytoskeletal re-arrangements must be initiated during Had, interest has focused on intracellular $\mathrm{Ca}^{2+}$ $\left(\left[\mathrm{Ca}^{2+}\right]_{\mathrm{i}}\right)$ changes during the interaction between root hairs and Nod factors. Recently, Ehrhardt et al. (1996) demonstrated periodic spiking of $\left[\mathrm{Ca}^{2+}\right]_{i}$ in the region proximal to the nucleus in response to homologous Nod factors in Medicago root hairs. This spiking response was often delayed by periods of up to $10 \mathrm{~min}$ (Ehrhardt et al. 1996) and is unlikely to cause the initial membrane depolarization that occurs within a minute of exposure to Nod factors. Spiking is preceded by plateau-like increases in $\left[\mathrm{Ca}^{2+}\right]_{\mathrm{i}}$ of variable length in several of the experiments reported by Ehrhardt et al. (1996), however, and these $\left[\mathrm{Ca}^{2+}\right]_{\mathrm{i}}$ increases may be of significance. Within an hour of these changes, the root-hair tip swells and this is followed by new tip growth, resulting in deformed root hairs (Heidstra et al. 1994).

Among rhizobia, Rhizobium sp. NGR234 is unique. It nodulates more than 110 genera of legumes as well as the nonlegume Parasponia andersonii. This broad host range is mediated by the excretion of a family of acetylated or sulfated Nod factors (NodNGR[Ac,S]) (Price et al. 1992). Similarly, the legume Vigna unguiculata (L.) Walp. nodulates with a broad range of Bradyrhizobium and Rhizobium spp. (Lewin et al. 1987). We use the combination of Rhizobium sp. NGR234 and $V$. unguiculata to analyze symbiotic specificity (Relić et al. 1993a). To investigate whether changes in $\left[\mathrm{Ca}^{2+}\right]_{i}$ occur within the first few minutes of the host response to Nod factors, we loaded root segments of $V$. unguiculata and the nonlegume nonhost Arabidopsis thaliana with the calcium indicators Fluo-3 and Fura-2. Root hairs and epidermal cells were examined by confocal laser scanning microscopy (CLSM) and ratiometric fluorescence microscopy. We found that NodNGR $[\mathrm{Ac}, \mathrm{S}]$ increased $\left[\mathrm{Ca}^{2+}\right]_{\mathrm{i}}$ levels in Had-competent root hairs and adjacent epidermal cells of $V$. unguiculata within $1 \mathrm{~min}$. Nod factors of $R$. meliloti caused equally rapid increases in $\left[\mathrm{Ca}^{2+}\right]_{\mathrm{i}}$ in the root hairs of the nonhost $V$. unguiculata, which also responds with root-hair deformation. Since the synthetic tetrasaccharide $N-N^{\prime}-N^{\prime \prime}-N^{\prime \prime \prime}$-tetracetylchitotetraose (TACT) represents the sugar backbone of Nod factors, it was also examined and found to have no effect on $\left[\mathrm{Ca}^{2+}\right]_{\mathrm{i}}$ in $\mathrm{V}$. unguiculata root hairs. The nonlegume nonhost A. thaliana showed neither $\left[\mathrm{Ca}^{2+}\right]_{\mathrm{i}}$ increases nor root-hair deformation, suggesting that Nod-factor-induced root-hair deformation is associated with increases in intracellular free calcium.

\section{RESULTS}

\section{Deformation of root hairs.}

Rhizobium sp. NGR234 forms nitrogen-fixing nodules on $V$. unguiculata (Table 1). Nodulation is preceded by deformation (Had) and curling (Hac) of infected root hairs. NodNGR[Ac,S] factors alone induce Had and Hac on $V$. unguiculata root hairs (Table 1). Factors released from $R$. meliloti, NodRmIV,V[Ac,S], also induce Had of $V$. unguiculata root hairs although this species does not nodulate $V$. unguiculata (Table 1). Although the acetoxymethyl (AM) esters of Fluo-3 or Fura-2 passively cross the plasma membrane and are cleaved to cell-impermeable adjuncts by intracellular esterases, loading and microscopic analysis would be facilitated if root segments rather than whole roots could be used. To test this, we first localized the region of the root on which root hairs respond to Nod factors. In essence, 3-day-old seedlings are the youngest that respond massively to rhizobia or Nod factors. As straight root hairs simplify microscopic observations, the seedlings were preincubated in the appropriate medium for $24 \mathrm{~h}$. Discrete sections of the root could then be excised and the effects of Nod factors determined in vitro. In whole plant experiments, three different root-hair response zones were evident (Fig. 1). Neither immature nor fully developed root hairs responded to treatment, while those intermediate in age showed all manner of deformations, including the onset of curling (Fig. 1C). Due to the size of the plant, this intermediate zone is much larger than in Vicia sativa subsp. nigra, but it corresponds to Zone II of Heidstra et al. (1994) and is referred to as the "newly mature root-hair zone" in this paper. One-minute exposure to NodNGR factors was sufficient to provoke bulbous deformations, while longer exposures ( $>4 \mathrm{~min}$ ) caused the formation of more classic Had response (Fig. 1). Time-lapse video microscopy showed that these deformations first became visible 1 to $2 \mathrm{~h}$ after Nodfactor addition, which is within the published range (Dazzo et al. 1996; Heidstra et al. 1994). To see if the same response could be observed in vitro, segments representing the young, newly mature, and mature zones of preincubated Vigna roots were excised and incubated in B \& D solution. After treatment with $10^{-9}$ M NodNGR234[Ac,S] factors, the deformations shown in Figure 2 were observed. Once again, only root hairs from the newly mature zone responded to treatment, and the types of deformation observed were similar to those found on the intact root (cf. Figures 1 and 2). Occasionally, small, irregular deformations attributable to washing were seen (Fig. 1C) but these could be readily distinguished from Nod-factorinduced deformations. There is little doubt that excised segments can be used for experiments of this type, at least for 24 to $48 \mathrm{~h}$ after excision.

Under standard conditions, $10^{-7}$ to $10^{-9} \mathrm{M}$ Nod factors from Rhizobium sp. NGR234 caused marked Had and Hac of root hairs in both plants and root segments. Nod factors from $R$. meliloti also caused marked Had of root hairs over this concentration range (Table 1). In contrast, the tetramer of $\mathrm{N}$ acetyl-D-glucosamine (TACT) had no visible effect on the root hairs (Table 1).

\section{Nod factors increase $\left[\mathrm{Ca}^{2+}\right]_{\mathrm{i}}$ in Had-competent root hairs and epidermal cells.}

Various methods of measuring $\left[\mathrm{Ca}^{2+}\right]_{i}$, particularly in Hadcompetent root hairs of $V$. unguiculata, were tested in preliminary experiments. A nonintrusive, ion-specific, vibrating micro-electrode (Kochian et al. 1992) was used in experiments performed in collaboration with J. Whittington and I. Newman (Physics Department, University of Tasmania, Hobart, Australia). Unfortunately, these methods lacked the sensitivity necessary to measure small and rapid changes. Methods involving microinjection of root hairs immobilized in alginate (Schnorf et al. 1991) were also tested. An advantage of these techniques is that they allow use of dextran-coupled dyes. Although Vigna root hairs are extremely rugged, it is possible to microinject, e.g., Calcium Green, and to monitor Nodfactor-induced changes in fluorescence by CLSM. In several experiments, we were able to show that Nod factors induced rapid, plateau-like increases in $\left[\mathrm{Ca}^{2+}\right]_{\mathrm{i}}$ (data not shown). Unfortunately, these methods are extremely laborious and are not 
readily adaptable to a large-scale surveys of root-hair responses to Nod factors. For these reasons, we decided to use two different techniques-ratiometric analysis with the dye Fura-2 to quantify the $\left[\mathrm{Ca}^{2+}\right]_{\mathrm{i}}$ response, and CLSM with Fluo3 to localize the responses within the root hairs. Both were performed on root segments loaded with the appropriate dye.

Root segments of $V$. unguiculata loaded with Fura-2 were aligned so that several root hairs were in focus; fluorescence was excited and followed by ratiometric microscopy. Increases in the fluorescent ratio correspond to increases in calcium. Experiments were undertaken either in the presence of calcium (B \& D solution, which includes $1 \mathrm{mM}$ calcium) or the absence of external calcium (B \& D solution minus calcium). The basal level of $\left[\mathrm{Ca}^{2+}\right]_{\mathrm{i}}$ in roots incubated in B \& D solution was variable but normally less than $300 \mathrm{nM}(n=12)$. Following application of the homologous Nod factor NodNGR[Ac,S] at $10^{-9} \mathrm{M}$ to root segments incubated in B \& $\mathrm{D}$ solution, the ratio increased from the steady basal level within seconds $(n=14$; Fig. $3 \mathrm{~A})$. The response reached a plateau almost immediately and remained relatively constant for the next 1 to $2 \mathrm{~min}$ prior to further additions. The trace depicted in Figure 3A demonstrates a dramatic increase from approximately 250 to $2,000 \mathrm{nM}$ free calcium (calculated as described in Materials and Methods). This increase occurred in response to application of homologous Nod factors and continued for the next $40 \mathrm{~s}$. It is not an atypical trace as both larger and smaller (e.g., Fig. 3B) increases in $\left[\mathrm{Ca}^{2+}\right]_{\mathrm{i}}$ were observed in other root segments in response to NodNGR[Ac,S] factors. At this stage, addition of EGTA (ethylene glycolbis( $\beta$-aminoethylether)- $N, N, N^{\prime}, N^{\prime}$-tetraacetic acid) was made to the root-segments, which decreased the ratio, indicating that $\left[\mathrm{Ca}^{2+}\right]_{\mathrm{i}}$ had fallen to near the original level. Such a response was seen whenever EGTA was added to root segments incubated in B \& D solution ( $n=14$; e.g., Fig. $3 \mathrm{~A}$ and D). The rapid, plateau-type response following addition of NodNGR[Ac,S] was observed with each preparation tested $(n$ $=14$ ), indicating that such increases in $\left[\mathrm{Ca}^{2+}\right]_{\mathrm{i}}$ are significant. This increased plateau response remained fairly constant for the next $2 \min (n=8)$. No further increase in $\left[\mathrm{Ca}^{2+}\right]_{i}$ was observed when the Nod-factor concentration was raised to $10^{-8}$ $\mathrm{M}$ at this stage $(n=3$; data not shown). The sustained, elevated $\left[\mathrm{Ca}^{2+}\right]_{\mathrm{i}}$ plateau in response to NodNGR[Ac,S] subsided of its own accord during the following $10 \mathrm{~min}$ and by 13 to 15 min was near the basal level ( $n=3$; Fig. 3B).

No such increases were observed when the Nod-factor solvent $(0.5 \%$ ethanol in $\mathrm{B} \& \mathrm{D}$ solution) was applied $(n=3$; data not shown) or the Nod-factor backbone TACT at $10^{-7}$ or $10^{-6} \mathrm{M}$ was applied to $V$. unguiculata root segments $(n=7$; Fig. 3C). Root segments still responded to NodNGR[Ac,S] at $10^{-9} \mathrm{M}$ following TACT application ( $n=3$; data not shown). In the example shown in Figure $3 \mathrm{C}$ the basal level of $\left[\mathrm{Ca}^{2+}\right]_{\mathrm{i}}$ was approximately $160 \mathrm{nM}$ and this dropped slightly following TACT application before returning to the pre-addition level. Interestingly, V. unguiculata root segments in B \& D solution also responded to the nonhomologous Nod factor, NodRmIV,V[Ac,S], at $10^{-9} \mathrm{M}$, by consistent, rapid, plateautype increases in the ratio (Fig. 3D). In the nonhomologous system, these increases in $\left[\mathrm{Ca}^{2+}\right]_{i}$ were variable. Sometimes they were relatively large, as shown in Figure 3D (rose from approximately 170 to $1,250 \mathrm{nM}$, a sevenfold increase) and at other times there were smaller but still marked increases of
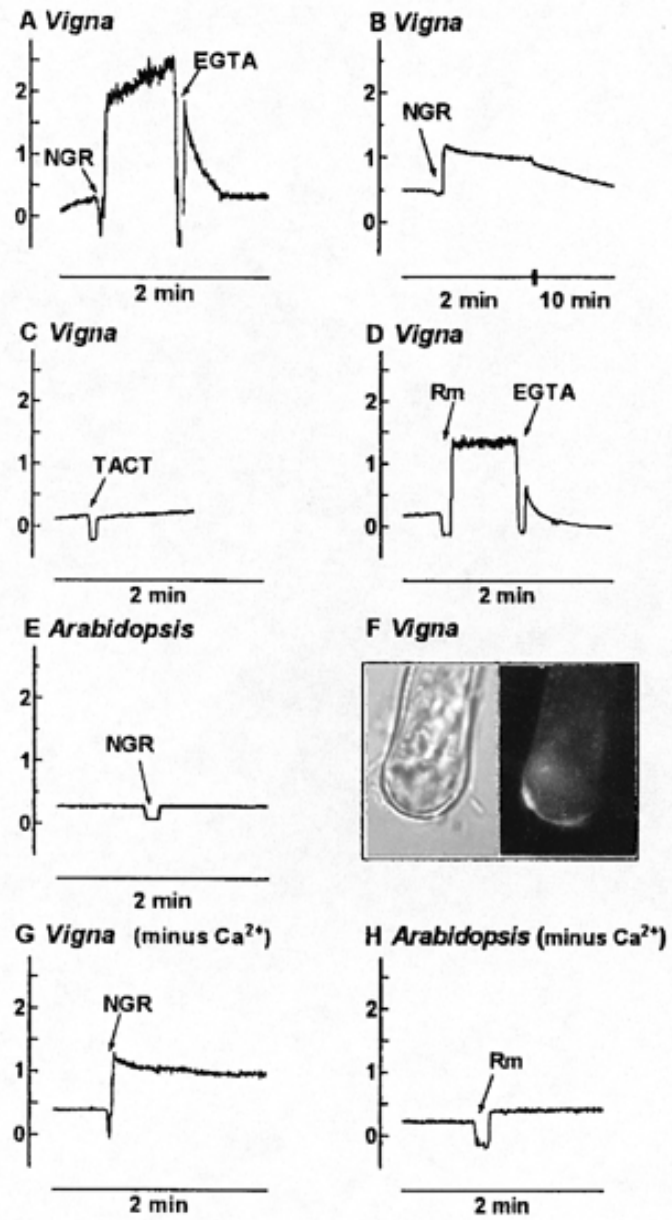

Fig. 3. $\mathrm{Ca}^{2+}$-dependent responses of Fura-2-loaded root segments incubated in B \& D solution with or without calcium. Ratio of fluorescence excited at 360 and $380 \mathrm{~nm}$ was recorded and used to estimate the $\left[\mathrm{Ca}^{2+}\right]_{\mathrm{i}}$, as described in Materials and Methods. $y$-axis represents $\left[\mathrm{Ca}^{2+}\right]_{\mathrm{i}}(\mu \mathrm{M})$. Basal $\left[\mathrm{Ca}^{2+}\right]_{\mathrm{i}}$ from Fura-2-loaded root segments of Vigna unguiculata incubated in $\mathrm{B} \& \mathrm{D}$ solution and the change in $\left[\mathrm{Ca}^{2+}\right]_{\mathrm{i}}$ following addition of (A) $10^{-9}$ M NodNGR[Ac,S] (which was then followed by addition of $25 \mathrm{mM}$ EGTA [ethylene glycol-bis( $\beta$-aminoethylether)- $N, N, N^{\prime}, N^{\prime}$-tetraacetic acid]), (B) $10^{-9} \mathrm{M}$ NodNGR[Ac,S] for $2 \mathrm{~min}$ (then the time scale was altered to allow the fluorescence ratio to be followed for the next 10 min), (C) $10^{-7} \mathrm{M}$ synthetic tetrasaccharide $N-N^{\prime}-N^{\prime \prime}-N^{\prime \prime \prime}$-tetracetylchitotetraose (TACT), and (D) $10^{-9} \mathrm{M}$ NodRmIV,V [Ac,S] (which was then followed by addition of $25 \mathrm{mM}$ EGTA). E, Basal $\left[\mathrm{Ca}^{2+}\right]_{\mathrm{i}}$ from Fura-2loaded root segments of Arabidopsis thaliana incubated in B \& D solution, and the change in $\left[\mathrm{Ca}^{2+}\right]_{i}$ following addition of $10^{-9} \mathrm{M}$ NodNGR[Ac,S]; similar results were seen following addition of either $10^{-6} \mathrm{M}$ TACT or $10^{-8} \mathrm{M}$ NodRmIV,V[Ac,S] to $A$. thaliana root segments incubated in B \& D solution. F, Light and fluorescent micrographs of a Fura-2-loaded, root-hair-tip segment of $V$. unguiculata incubated in B \& D solution. Root hair was viewed with a Leitz Dialux 22 microscope through a PL APO 25/0.70 objective. Fluorescence was excited at 360 $\mathrm{nm}$; emitted signal collected above $510 \mathrm{~nm}$. Basal $\left[\mathrm{Ca}^{2+}\right]_{\mathrm{i}}$ from Fura-2loaded root segments of $(\mathbf{G}) V$. unguiculata and $(\mathbf{H})$ A. thaliana, incubated in $B \& D$ solution minus calcium, and the change in $\left[\mathrm{Ca}^{2+}\right]_{i}$ following addition of (G) $10^{-9} \mathrm{M}$ NodNGR[Ac,S] and (H) $10^{-9} \mathrm{M}$ NodRmIV,V[Ac,S]. (H) is an example of the maximum response observed following any treatment of $A$. thaliana root segments. 
approximately 300 to $400 \mathrm{nM}$, reflecting two- to threefold increases $(n=9)$. We also tested the effect of NodNGR[Ac,S] on A. thaliana root segments loaded with Fura-2 and incubated in B \& D solution. Neither NodNGR[Ac,S] at $10^{-9}$ to $10^{-7} \mathrm{M}\left(n=7\right.$; Fig. 3E), nor NodRmIV,V[Ac,S] at $10^{-8} \mathrm{M}(n=$ 4; data not shown), nor TACT at $10^{-7}$ or $10^{-6} \mathrm{M}(n=3$; data not shown) had any effect on $A$. thaliana root segments.

Experiments were also undertaken with root segments that had been loaded and treated in B \& D solution minus calcium to determine if the same type of responses occurred. Both the homologous Nod factor, NodNGR[Ac,S], at $10^{-9} \mathrm{M}(n=8$; Fig. 3G), and the nonhomologous Nod factor, NodRmIV,V[Ac,S], at $10^{-9} \mathrm{M}(n=7$; data not shown), induced rapid and persistent plateau-type responses in $\left[\mathrm{Ca}^{2+}\right]_{i}$. In the example depicted in Figure 3G, NodNGR[Ac,S] induced the basal $\left[\mathrm{Ca}^{2+}\right]_{\mathrm{i}}$ to rise from approximately 400 to $1,100 \mathrm{nM}$ (a 2.8-fold increase), which then fell to approximately $950 \mathrm{nM}$ over the next minute. Upon addition of calcium, $\left[\mathrm{Ca}^{2+}\right]_{\mathrm{i}}$ was further increased after the treatment with the homologous Nod factor ( $n=3$; data not shown). These changes in root segments incubated in B \& D solution minus calcium in response to either Nod factor (also in B \& D solution minus calcium) could be reversed by the application of EGTA $(n=12$; data not shown). Similar response trends to either Nod factor were observed with each preparation tested, indicating that such increases in $\left[\mathrm{Ca}^{2+}\right]_{\mathrm{i}}$ are significant. The nonhost $A$. thaliana did not respond to the Nod factor NodNGR[Ac,S] with any significant change in the fluorescence ratio when incubated in B \& D minus calcium ( $n=5$; data not shown). However, these root segments were capable of responding to the addition of external calcium by increases in $\left[\mathrm{Ca}^{2+}\right]_{\mathrm{i}}(n=3$; data not shown). An example of the maximum response observed in $A$. thaliana root segments to Nod factors is shown in Figure $3 \mathrm{H}$ :
NodRmIV,V[Ac,S $]$ at $10^{-9} \mathrm{M}(n=3)$ stimulated the nonsignificant increase from approximately 230 to $350 \mathrm{nM}$ (a 1.5fold increase). Increases of this order were also seen in response to TACT by $V$. unguiculata roots loaded and treated in B \& D solution minus calcium ( $n=4$; data not shown). Such root segments could respond to the addition of external calcium by significant increases in fluorescence ratio, indicating an increase in $\left[\mathrm{Ca}^{2+}\right]_{\mathrm{i}}(n=6)$.

Although the results reported above indicate that $\left[\mathrm{Ca}^{2+}\right]_{\mathrm{i}}$ increases in response to Nod factors in $V$. unguiculata, but not $A$. thaliana, root segments, the resolution obtained with the ratiometric system that we used was insufficient to determine which part of the root hairs was responding. To determine the responsive region, root segments were loaded with Fluo-3, excited at $488 \mathrm{~nm}$, and viewed by CLSM. Fluo-3 preferentially accumulated around the nucleus of Petroselinum crispum, which was located near the tip (Fig. 4A,B). Fortunately, the nuclei had retreated from the tips of the newly mature $A$. thaliana (Fig. 4C,D) and Vigna (Fig. 4E,F) root hairs, and Fluo-3 was more or less evenly distributed in the cytoplasm at their extremities. Since the major changes in $\left[\mathrm{Ca}^{2+}\right]_{\mathrm{i}}$ occur near the tips (Fig. 5J), irregularities in Fluo-3 loading were of minor importance in analyzing the spatial distribution of changes in $\left[\mathrm{Ca}^{2+}\right]_{\mathrm{i}}$.

Using Fluo-3-loaded root segments, we were able to confirm that Nod factors do not affect $\left[\mathrm{Ca}^{2+}\right]_{\mathrm{i}}$ in root cells of nonlegumes. Following application of NodNGR[Ac,S] at $10^{-7}$ $\mathrm{M}$, no changes in fluorescence were observed in newly mature root hairs of $P$. crispum (Fig. 4A,B) or the epidermal cells of the root segments $(n=5)$. The tips of the newly mature root hairs of $A$. thaliana did not alter their fluorescence intensity significantly following treatment with NodNGR[Ac,S] at $10^{-8}$ M (Fig. 4C,D) and epidermal cells were also unaffected $(n=$
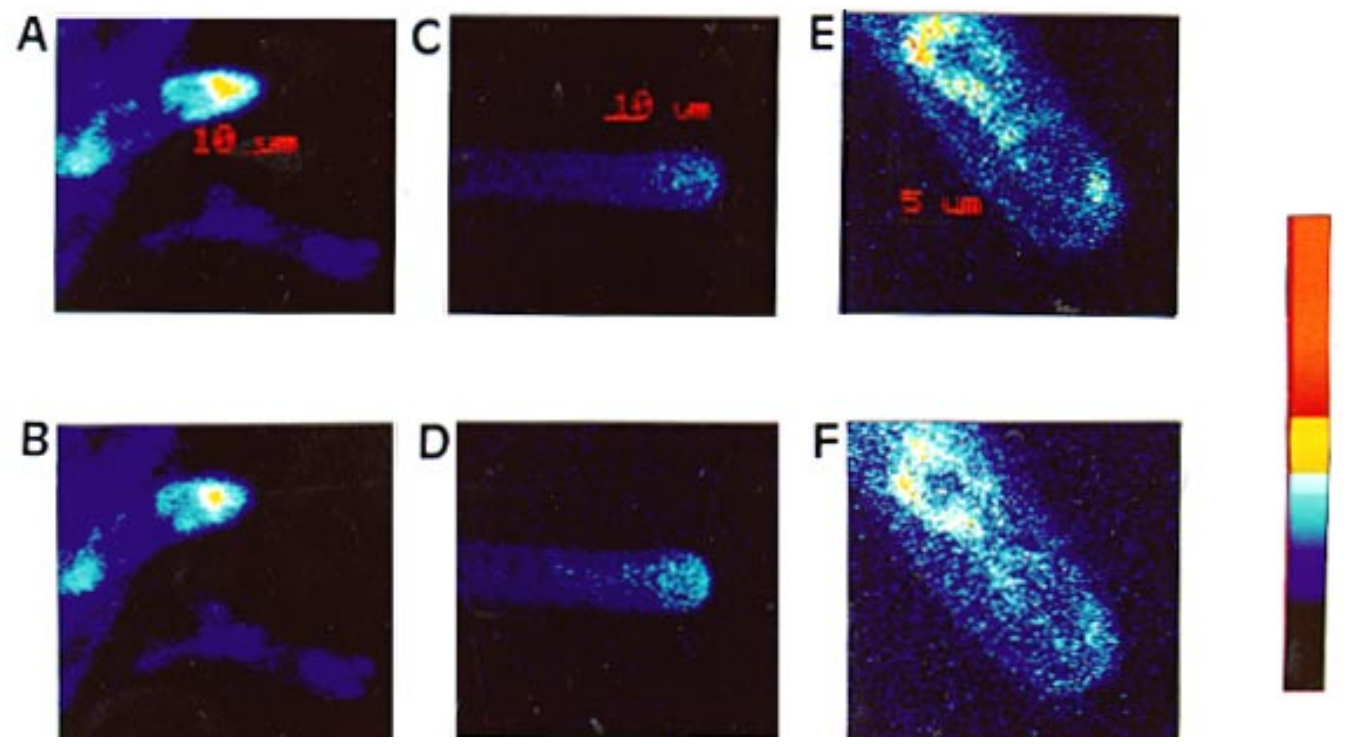

Fig. 4. $\left[\mathrm{Ca}^{2+}\right]$-dependent responses of root hairs of nonlegumes to Nod[Ac,S] and Vigna unguiculata to synthetic tetrasaccharide $N-N^{\prime}-N^{\prime \prime}-N^{\prime \prime \prime}-$ tetracetylchitotetraose (TACT). A and B, Computer-generated, confocal fluorescent images of a root hair of a Fluo-3-loaded root segment of Petroselinum crispum. Images were taken 1 (A) and 7 (B) min following addition of 10-7 M NodNGR[Ac,S]. Objective: PL fluotar 10/0.3. Bar: 10 $\mu \mathrm{m}$. C and $\mathbf{D}$, Computer-generated, confocal fluorescent images of a root hair of a Fluo-3-loaded root segment of Arabidopsis thaliana. Images were taken 1 min before (C) and 6 min following (D) addition of $10^{-7}$ M NodNGR[Ac,S]. Objective: PL fluotar 40/0.3-oil. Bar: $10 \mu \mathrm{m}$. E and F, Computer-generated, confocal fluorescent images of a root-hair of a Fluo-3-loaded root segment of $V$. unguiculata. Images were taken $1(\mathbf{E})$ and $7(\mathbf{F})$ min following addition of $10^{-7}$ M TACT. Objective: PL fluotar 40/0.3-oil. Bar: $5 \mu \mathrm{m}$. Color bar represents a range of [ $\mathrm{Ca}^{2+}$ from low (blue) to high (red). 
4). A slight but nonsignificant increase in fluorescence occurs at the tip of the root hair (Fig. 4C,D), which reflects the brightest plane of the root-hair tip observed in the 10-min time course following treatment with NodNGR[Ac,S]. Similarly, neither $10^{-10}$ nor $10^{-7} \mathrm{M}$ NodNGR[Ac,S] factors altered $\left[\mathrm{Ca}^{2+}\right]_{\mathrm{i}}$ in root hairs or epidermal cells of the monocotyledon Zea mays over a 10-min imaging period $(n=5$; data not shown). No changes in fluorescence of newly mature root hairs of $V$. unguiculata were observed following TACT $\left(10^{-6}\right.$ M) treatment (Fig. 4E,F), confirming that the oligosaccharide backbone does not modulate $\left[\mathrm{Ca}^{2+}\right]_{\mathrm{i}}$ in susceptible root hairs $(n=3)$.

Using Fluo-3-loaded V. unguiculata root segments from the zone of newly mature root hairs, we confirmed the increases observed in Fura-2-loaded root segments following treatment with the Nod factors. Increases in fluorescence at the tip of a newly mature root hair could be detected within 2 min of exposure to NodNGR[Ac,S] at $10^{-8} \mathrm{M}$ (Fig. 5). The increase is most apparent at the very tip of the root hair, with most of the change occurring in the first $2 \mathrm{~min}$ although increases also occur farther away (Fig. 5J). In addition, increased fluorescence also appears in punctate fluorescent areas within the root hair. We consistently observed an increase in fluorescence in response to Nod factors at the root-hair tip. In some experiments, longer incubation times were necessary to observe increases in fluorescence, presumably to allow the factor to diffuse to the root segment. When $V$. unguiculata root segments were viewed under lower magnification, complete root hairs and epidermal cells were observed. Addition of $10^{-9}$ to $10^{-10} \mathrm{M}$ NodNGR[Ac,S] factors to these root segments resulted in a steady increase of fluorescence in the root hair and epidermal cell cytoplasmic region over 2 to $15 \min (n=9$; data not shown). In addition, in some root hairs we observed no change in fluorescence in response to Nod factors $(n=4$; data not shown). This lack of response may be due to the advanced developmental stage of the root hairs in the zone adjacent to the Nod-factor-responsive, newly mature root hairs of the root segment. When the epidermal cells were also in focus in the just-mature root-hair zone, the changes appeared to be greater in the basal region of the root hair and the epidermal region than at the tip alone. This is rather difficult to quantify for several reasons. First, when the base of the root hair is in focus, the tip is usually only partly or not at all in focus. Second, the basal regions of the hair and epidermal cells are thicker than the tip region and accumulate more dye, which can lead to artifactual increases in fluorescence due to uneven dye distribution that cannot be corrected for with Fluo-3. Last, dye accumulation in small, intracellular organelles may be more of a problem within the epidermal cells than it appears to be in the tip of root hairs responsive to Nod factors (for a discussion of these and other problems, see Read et al. 1992). Changes in fluorescence in response to the nonhomologous
A
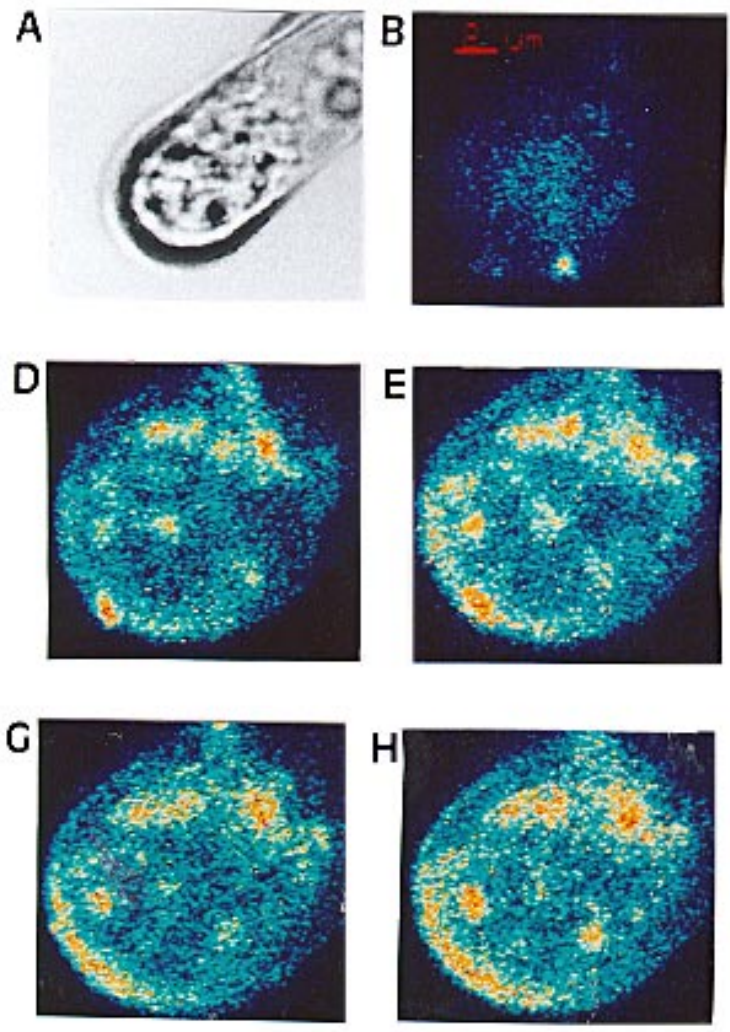
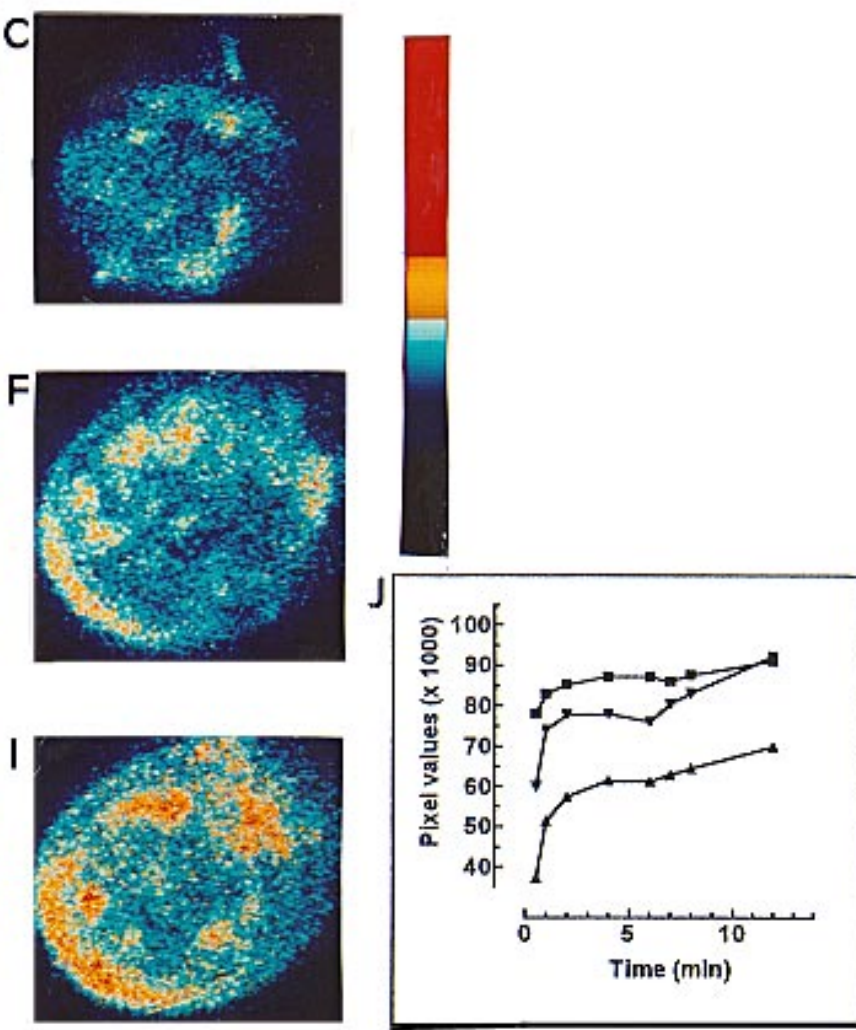

Fig. 5. Changes in $\left[\mathrm{Ca}^{2+}\right]$-dependent intracellular fluorescence of a Vigna unguiculata root hair in response to NodNGR[Ac,S]. A, Light micrograph of the root hair loaded with Fluo-3, enlarged to show tip region followed in B-I. Objective: PL fluotar 40/0.3-oil. B-I, Computer-generated, confocal fluorescent images of tip of root hair following addition of $10^{-8} \mathrm{M}$ NodNGR[Ac,S]. Images were taken $0.5(\mathbf{B}), 1(\mathbf{C}), 2(\mathbf{D}), 4(\mathbf{E}), 6(\mathbf{F}), 7$ (G), 8 (H), and 12 (I) min after addition of NodNGR[Ac,S] to the B \& D solution. Color bar represents a range of $\left[\mathrm{Ca}^{2+}\right]$ from low (blue) to high (red). Bar: $2 \mu \mathrm{m}$. J, Graphical representation of the changes in total pixel values that occur after treatment of the V. unguiculata root hair (B-I) above: mid section ( $\mathbf{\square})$ of root-hair tip that is pale blue in $\mathbf{B}$; the tip region $(\mathbf{A})$, which markedly increases in fluorescence during time course in $\mathbf{B}-\mathbf{I}$; and lower region $(\boldsymbol{\nabla})$ of roothair tip adjacent to and to the right of the bright fluorescent spot in $\mathbf{B}$. 
Nod factor NodRmlV,V[Ac,S] at $10^{-9} \mathrm{M}$ were monitored in Fluo-3-loaded root hairs of $V$. unguiculata $(n=5)$. In the example depicted in Figure 6, the increase in fluorescence was rapid and appeared to have a slight peak 2 min after addition of NodRmIV,V[Ac,S] although the fluorescence remained higher than the basal level for the next $10 \mathrm{~min}$.

\section{DISCUSSION}

In his pioneering studies, Prazmowski found that the tip of Pisum sativum root hairs treated with $R$. leguminosarum rolled together in a "hirtenstabförmigen" (assuming the form of a "Shepherd's crook") manner (see Hiltner 1900). Since then, countless others have confirmed his observations and shown that formation of a "Shepherd's crook" is a prelude to nodulation (e.g., Vincent 1974). Indeed, it has become part of the dogma of rhizobiology that "Shepherd's crook"-type curling of the root hairs (Hac) is the first truly specific step in the symbiosis (see Yao and Vincent 1969). V. unguiculata has a very similar early response to Nod factors of either Rhizobium sp. NGR234 or R. meliloti RC2011. Both provoke Had and Hac (Fig. 1; Table 1). In other words, certain Nod factorlegume combinations provoke $\mathrm{Had}$ (or $\mathrm{Hac}$ ) without regard to the nodulation ability of the rhizobia from which they were isolated (Mylona et al. 1995; Relić et al. 1993b, 1995). In this case, $R$. meliloti RCR2011 cannot nodulate V. unguiculata although its Nod factor, NodRmIV,V[Ac,S], stimulates Had (Table 1).
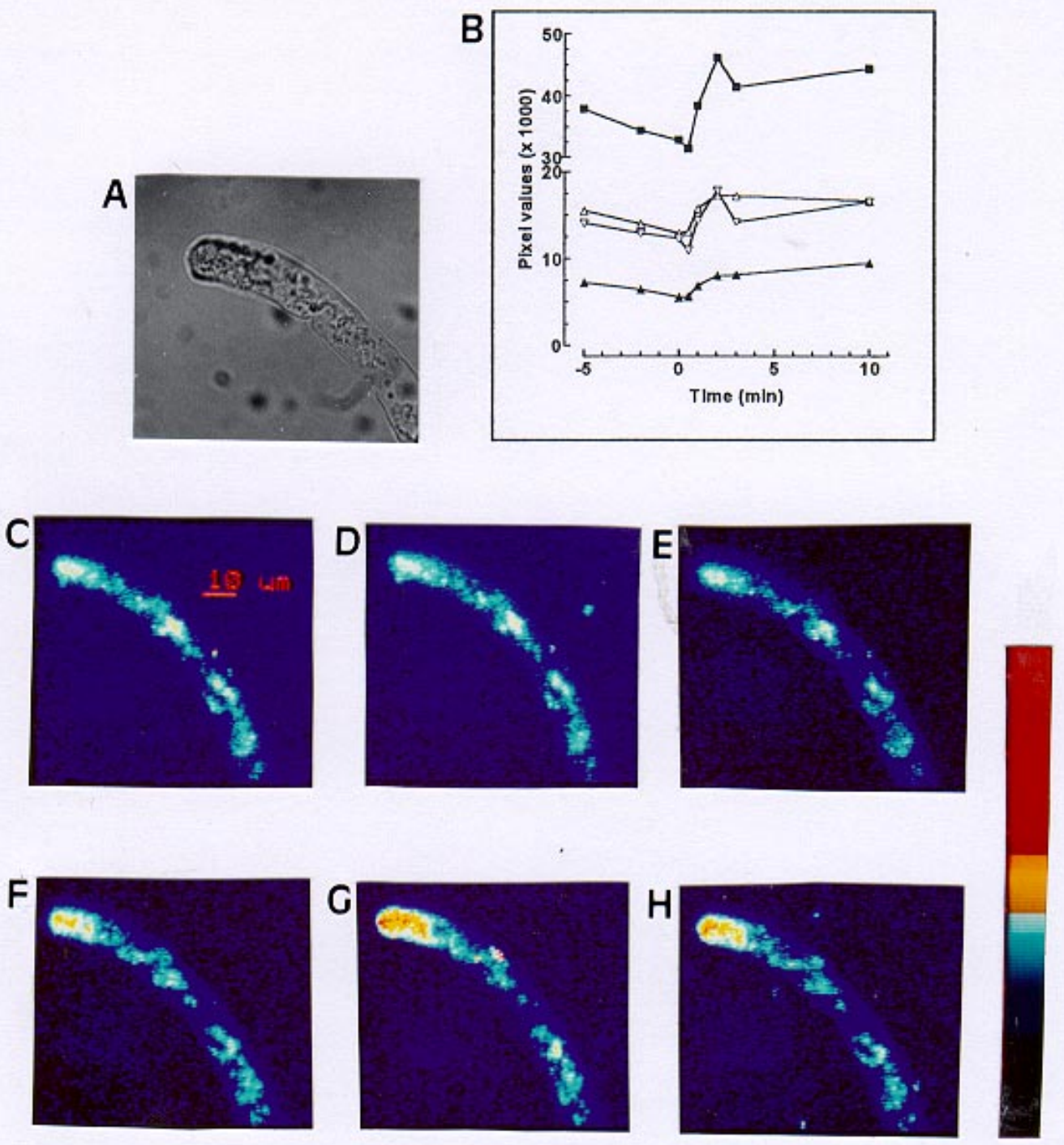

Fig. 6. Changes in $\left[\mathrm{Ca}^{2+}\right]$-dependent intracellular fluorescence of a Vigna unguiculata root hair in response to NodRmIV,V[Ac,S]. A, Light micrograph of the root-hair tip loaded with Fluo-3 followed in C-H. Objective: PL fluotar 40/0.3-oil. B, Graphical representation of the changes in total pixel values that occur before and after treatment of the V. unguiculata root hair $(\mathbf{C}-\mathbf{H})$ with $10^{-9} \mathrm{M}$ NodRmIV,V[Ac,S]: overall responsive bright area $(\mathbf{\square})$ of the root-hair tip in $\mathbf{C}$; the very tip of the root hair $(\mathbf{\Delta})$, the upper region of the root hair (inverted open triangle) and the lower region of the root-hair tip ( $\Delta$ ) corresponding to the upper and lower parts of the region followed $(\boldsymbol{\square})$. C-H, Computer-generated, confocal fluorescent images of the root-hair tip before and after addition of $10^{-9} \mathrm{M}$ NodRmIV,V[Ac,S]. Images were taken $2(\mathbf{C})$ and $0.2(\mathbf{D})$ min before addition of NodRmIV,V[Ac,S]. The following images were taken $0.5(\mathbf{E}), 1(\mathbf{F}), 2(\mathbf{G})$, and $3(\mathbf{H})$ min after addition of NodRmIV,V[Ac,S] to the B \& D solution. Color bar represents a range of [Ca $\left.{ }^{2+}\right]$ from low (blue) to high (red). Bar: $10 \mu \mathrm{m}$. 
It is becoming apparent that the spatial occurrence in $\left[\mathrm{Ca}^{2+}\right]_{\mathrm{i}}$ changes, and possibly the degree of $\left[\mathrm{Ca}^{2+}\right]_{i}$ change, are important in the signaling processes in plant cells (Bush 1995). It is thus possible that the site of $\left[\mathrm{Ca}^{2+}\right]_{\mathrm{i}}$ change may represent one of the first specific molecular events in the infection process. We found that changes in $\left[\mathrm{Ca}^{2+}\right]_{i}$ in newly mature root hairs consistently occur and mirror root-hair deformation patterns. Thus, increases in $\left[\mathrm{Ca}^{2+}\right]_{\mathrm{i}}$ in $V$. unguiculata root hairs follow application of either homologous NodNGR[Ac,S] or nonhomologous NodRmIV,V[Ac,S] factors (Figs. 3, 5, and 6). The increase in $\left[\mathrm{Ca}^{2+}\right]_{\mathrm{i}}$ in $V$. unguiculata root hairs and epidermal cells occurs within seconds of receipt of applied Nod factors. When the Nod factor is added directly to the specimen, the change is within seconds (Fig. 3) whereas a slower change is observed when the Nod factor is allowed to diffuse to the root hairs (Figs. 5 and 6). Increases in $\left[\mathrm{Ca}^{2+}\right]_{\mathrm{i}}$ occur with or precede the slow depolarization observed in $M$. sativa root hairs following application of the homologous Nod factor (Ehrhardt et al. 1992; Felle et al. 1995; Kurkdjian 1995). The increase in $\left[\mathrm{Ca}^{2+}\right]_{\mathrm{i}}$ that we report in this paper occurs prior to the periodic calcium spiking associated with the nucleus in $M$. sativa root hairs that eventuates several minutes after addition of homologous Nod factors (Ehrhardt et al. 1996). Such spiking occurs asynchronously in adjacent root hairs and is only clearly detected near the nucleus (see Ehrhardt et al. 1996). In our Fura-2 experiments (Fig. 3), the response of several root hairs was recorded at the same time. If it occurred, asynchronous, periodic calcium spiking within individual root hairs would thus form part of the total fluorescent response that we measured. When measurements were taken 10 to $20 \mathrm{~min}$ after application of homologous or nonhomologous Nod factors to Vigna root segments loaded with Fura-2, spiking was observed with a periodicity of approximately $1 \mathrm{~min}$ (data not shown). As explained above, this spiking is difficult to observe in our set-up because we record the cumulative responses of several root hairs simultaneously. Thus, whether this response represents the spiking observed by Ehrhardt et al. (1996) remains to be determined.

Where the $\left[\mathrm{Ca}^{2+}\right]_{\mathrm{i}}$ actually rises within the cell is also difficult to determine. In the Fluo-3 experiments, we examined the area at the tip of the root hair where a relatively rapid response occurred (increases within 2 min; Figs. 5 and 6). Clearly, increases in cytoplasmic $\mathrm{Ca}^{2+}$ occur at the tip of the root hair (Figs. 5 and 6) in response to Nod-factor application, although some punctate areas, which presumably represent small organelles, also increase in fluorescence (and possibly $\mathrm{Ca}^{2+}$ ). We did not observe periodic spiking in the tip area, which is in agreement with the data of Ehrhardt et al. (1996), who reported that periodic calcium spiking is confined to the nuclear region. In our experiments, the region near the nucleus in the Fluo-3-loaded root hairs showed a greater degree of punctate fluorescence, presumably representing dye accumulation in small organelles. Measurement of changes in fluorescence in areas containing high levels of punctate fluorescence is fraught with difficulty and does not necessarily reflect changes in $\left[\mathrm{Ca}^{2+}\right]_{\mathrm{i}}$ (see Read et al. 1992 for discussion) and so we did not attempt to measure specific changes in this region. Ehrhardt et al. (1996) microinjected M. sativa root hairs with either dextran-linked Calcium Green or Fura-2 to reduce punctate fluorescence and observed periodic calcium spiking in the nuclear region, usually 5 to $15 \mathrm{~min}$ after application of homologous Nod factor. We have not observed marked increases in fluorescence in vacuolar regions. However, $\mathrm{Ca}^{2+}$ may accumulate in the vacuole or the vacuole may represent the source and eventual store of $\mathrm{Ca}^{2+}$ in the cell (for discussion, see Bush 1995). In some experiments, we exposed root segments to prolonged loading (over $2 \mathrm{~h}$ ) with Fura-2 and these traces showed a significantly higher basal ratio, which could be due to dye accumulation in both the cytoplasm and vacuole. Although such root segments were not normally used in our experiments, they were capable of responding to the addition of external calcium with further increases in the signal ratio. To reduce possible complications with dye accumulating in the vacuole (see Ayling et al. 1994; Read et al. 1992), we routinely used root segments that had been loaded for $1 \mathrm{~h}$ only and that had a consistent basal fluorescent ratio. In the experiments in B \& D minus calcium (e.g., Fig. 3G) a transient peak was observed that declined to a plateau well above the basal level. The response can be reversed by application of EGTA to remove external calcium, possibly indicating that it could eventually return to basal levels.

It is noteworthy that the $\left[\mathrm{Ca}^{2+}\right]_{\mathrm{i}}$ increase is a plateau-type response (Fig. 3) rather than a sharp transient peak. The $\left[\mathrm{Ca}^{2+}\right]_{\mathrm{i}}$ response that we observed continues for a relatively long time (at least for minutes) before declining to basal levels (Fig. 3B). It is during this decline period that the periodic calcium spiking observed by Ehrhardt et al. (1996) occurs. In the $M$. sativa system used by Ehrhardt et al. (1996), the characteristic calcium spiking was only observed if the Fura-2injected cells were not irradiated prior to Nod-factor application. In the Vigna system, we are able to load root segments with Fura-2 and observe fluorescent changes in the root hairs without any constraints. Our results reveal a characteristic and immediate plateau response of sustained elevated calcium following application of either homologous or nonhomologous Nod factors (Fig. 3). These responses were consistently 3- to tenfold over the basal level of fluorescence ratio and lasted for a period of at least $10 \mathrm{~min}$ (Fig. 3). The responses appear to correlate directly with the ability of Nod factors to induce Had (or Hac). Interestingly, Ehrhardt et al. (1996) also observed a plateau-type increase immediately following application of homologous Nod factors (with Calcium Green-injected root hairs-refer in particular to Fig. 5B of Ehrhardt et al. 1996) and preceding the spiking response. Additionally, the increase in $\left[\mathrm{Ca}^{2+}\right]_{\mathrm{i}}$ occurs in the tip of the root hair (Figs. 5 and 6), where the developing cell wall is most immature (Aeschbacher et al. 1994).

Attempts to localize the source of the increases in intracellular calcium were inconclusive. In ratiometric experiments in which the calcium chelator EGTA was added directly to the root segments, $\left[\mathrm{Ca}^{2+}\right]_{\mathrm{i}}$ decreased rapidly (Fig. 3A,D), suggesting that $\mathrm{Ca}^{2+}$ came from external sources. It is also possible that EGTA could chelate external stores and thus have an indirect effect on internal compartments. On the other hand, similar, plateau-like increases in $\left[\mathrm{Ca}^{2+}\right]_{\mathrm{i}}$ were seen in experiments in which the root segments were incubated either in the normal nutrient solution or in calcium-free media (cf. Fig. 3B and $\mathrm{G}$ ). These data point to liberation of $\mathrm{Ca}^{2+}$ from internal, cytoplasmic compartments. On the other hand, it is possible that the calcium concentration outside plant cells is large and cannot be simply eliminated by excluding $\mathrm{Ca}^{2+}$ from the bathing solution. 
We believe that these data show that Nod factors modulate $\left[\mathrm{Ca}^{2+}\right]_{\mathrm{i}}$ levels in Had-competent root hairs by Nod factors for the following reasons. First, Nod factors have no effect on $\left[\mathrm{Ca}^{2+}\right]_{\mathrm{i}}$ in the root hairs and epidermal cells of the nonlegume nonhosts A. thaliana, P. crispum, and Z. mays. Second, TACT, the glucosamine backbone of the Nod factors, had no significant effect on the $\left[\mathrm{Ca}^{2+}\right]_{\mathrm{i}}$ levels of any tissues on which it was tested. Third, the Nod-factor levels that induce these $\left[\mathrm{Ca}^{2+}\right]_{\mathrm{i}}$ changes $\left(10^{-9} \mathrm{M}\right)$ are equivalent to those that cause root-hair deformation (Table 1; Relić et al. 1995). Last, Nod factors modulate intracellular $\mathrm{Ca}^{2+}$ levels in those tissues known to respond to them (i.e., root hairs, particularly the tips but also epidermal cells). That these $\left[\mathrm{Ca}^{2+}\right]_{\mathrm{i}}$ changes occur in not only root-hair cells but also neighboring epidermal cells is consistent with the spatial distribution of the Rhizobium-induced peroxidase activity (Cook et al. 1995) apparent in Medicago trunculata.

For these reasons, we suggest that Nod factors are stimuli that elevate $\left[\mathrm{Ca}^{2+}\right]_{\mathrm{i}}$ in root hairs and epidermal cells prior to inducing root-hair deformation. This elevation may be associated with membrane depolarization of the root hairs in response to homologous Nod factors (Ehrhardt et al. 1992; Felle et al. 1995; Kurkdjian 1995). The increased $\left[\mathrm{Ca}^{2+}\right]_{\mathrm{i}}$ could arise via an increased influx of extracellular $\mathrm{Ca}^{2+}$ through calcium channels in the plasma membrane of the root hairs, or by the release of sequestered $\mathrm{Ca}^{2+}$ from intracellular compartments, or from a combination of both (for discussion, see Bush 1995). Available evidence suggests that the latter case is more likely. For instance, a transient influx of $\mathrm{Ca}^{2+}$ is observed following application of homologous Nod factors (Allen et al. 1994), indicating an external source. The periodic calcium spikes observed by Ehrhardt et al. (1996) suggest that calcium is being released from an internal store associated with the nucleus and then being taken up again. The prolonged, plateau-type nature of the response is of great interest. Such a change is unlikely to induce specific, rapidly modulated events, which are more likely to be stimulated by high transient changes in $\left[\mathrm{Ca}^{2+}\right]_{i}$. This prolonged increase may be required to initiate transcriptional activation of genes involved in re-orientation of root-hair growth whereas periodic spiking is perhaps necessary to control the rate of differentiation (cf. Dolmetsch et al. 1997).

\section{MATERIALS AND METHODS}

\section{Bacteria, Nod factors, and plants.}

A Rif ${ }^{\mathrm{T}}$ derivative of Rhizobium sp. NGR234 (Stanley et al. 1988) and a $\mathrm{Tc}^{\mathrm{r}}$ isolate of $R$. meliloti RCR2011 (Rosenberg et al. 1981) were raised under standard conditions (Broughton et al. 1985). Nod factors were isolated from cultures of Rhizobium sp. NGR234(pA28) (Price et al. 1992) and R. meliloti strain 2011(pMH683) (Roche et al. 1991) by the published procedures. Nod factors were $\geq 99 \%$ pure as shown by proton nuclear mass resonance and fast-atom bombardment mass spectroscopy. Nod-factor nomenclature follows the suggestions of Roche et al. (1991). Seeds of Vigna unguiculata (L.) Walp. var. Red Caloona, A. thaliana, Petroselinum crispum, and Zea mays were surface sterilized in concentrated $\mathrm{H}_{2} \mathrm{SO}_{4}$ for $5 \mathrm{~min}$ and rinsed extensively in sterile $\mathrm{H}_{2} \mathrm{O}$. The seeds were germinated on $\mathrm{B} \& \mathrm{D}$ agar (Broughton and Dilworth $1971)$ at 27 to $28^{\circ} \mathrm{C}$ and roots harvested for $\left[\mathrm{Ca}^{2+}\right]_{i}$ experi- ments at 3 days. In some instances, A. thaliana liquid-cultured roots containing root hairs at the just-mature stage were used instead. There appeared to be no difference in the $\left[\mathrm{Ca}^{2+}\right]_{\mathrm{i}}$ responses of seed-germinated roots, compared with liquidcultured roots. Tests for nodulation were performed in Magenta jars under standard conditions (Lewin et al. 1990).

\section{Root-hair deformation assays.}

Nod factors of Rhizobium sp. NGR234 and R. meliloti RCR2011 were tested for their ability to deform (Had) and curl (Hac) root hairs of $V$. unguiculata as previously described (Price et al. 1992). To define the susceptible region of the root, two different kinds of experiment were performed. In one, sterile 2-day-old $V$. unguiculata seedlings were placed in modified microcentrifuge tubes suspended just above $9 \mathrm{ml}$ of B \& D solution contained in painted test tubes (Price et al. 1992). After $24 \mathrm{~h}$ of growth (days: $30^{\circ} \mathrm{C}, 350 \mu \mathrm{E} \cdot \mathrm{s}^{-1} \cdot \mathrm{m}^{-2}$ photosynthetically active radiation; nights: $20^{\circ} \mathrm{C}$; both including a 1-h stepped "sunrise" and a 1-h stepped "sunset"), 1 $\mathrm{ml}$ of $10^{-8} \mathrm{M}$ NodNGR[Ac,S] was added to the B \& D solution, and "washed-out" by repeated rinsing (minimum four times) with $10 \mathrm{ml}$ of B \& D solution at 1, 2, 4, 8, 16, 32, and $64 \mathrm{~min}$ after Nod-factor addition. Following a further overnight incubation, the roots were excised and stained with methylene blue (Vasse and Truchet 1984). A combination of bright- and dark-field microscopy allowed definition of the zone containing receptive root hairs (Fig. 1). In another series of experiments, selected 2-day-old $V$. unguiculata seedlings were transferred to B \& D agar contained in 14.5-cm- diameter petri dishes. A $10 \times 0.5 \mathrm{~cm}$ slot was cut in the agar, and the seed with the emerging root attached was placed in the slot so that the seedlings would not fall when the petri dishes were placed in the vertical position. After incubation (for $24 \mathrm{~h}$ at $27^{\circ} \mathrm{C}$ in the dark) in the vertical position, 10 - to 20 -mm segments of the receptive zone were excised and incubated $(24 \mathrm{~h}$ at $27^{\circ} \mathrm{C}$ in the dark) in $10^{-9} \mathrm{M}$ NodNGR234[Ac,S] dissolved in $\mathrm{B} \& \mathrm{D}$ solution. Microscopic examination of the methylene blue-stained segments showed that root hairs on the excised segments are capable of responding to NodNGR factors in terms of Had and Hac (Fig. 2).

\section{Loading root segments with intracellular calcium indicators.}

Segments (3 to $4 \mathrm{~mm}$ long) were cut from the region of justmature root hairs of the root. The segments were incubated in B \& D solution containing $20 \mu \mathrm{M}$ of acetyoxymethyl esterified (AM) form of either Fura-2 in the presence of $0.1 \%$ Pluronic F-127 or Fluo-3 (Molecular Probes, Eugene, OR). The AM form of these dyes is not responsive to calcium but it is permeable to membranes and can readily penetrate the cell, where the dyes are cleaved to their active, calcium-indicating forms by endogenous hydrolases. Loading was performed in the dark at 20 to $25^{\circ} \mathrm{C}$ for $1 \mathrm{~h}$ (Gehring et al. 1990) and terminated by extensive rinsing in B \& D solution. In some instances, loading and all following treatments were done with calcium-free B \& D solution (indicated in the text). Root segments loaded with Fura-2 were examined by light and epifluorescence microscopy to determine the intracellular location of the dye (Fig. 3F). The dye was predominantly found in cytoplasmic regions although some dye had accumulated in small organelles, as evinced by discrete punctate regions. 
Root segments loaded with Fluo-3 were viewed by light and confocal microscopy and the majority of the dye was found in the cytoplasm (see below). Once the cells were loaded, the response to the Nod factors was followed with fluorescent ratiometric or confocal microscopy and the results analyzed qualitatively.

\section{Fluorescence ratio imaging.}

Fura-2-loaded root segments were fixed between two glass coverslips although the viewed part remained uncovered but submersed in a 50- $\mu 1$ drop of B \& D solution. Additions were made directly to the drop containing the specimen. The root segments were viewed with an Olympus inverted microscope and excited at 360 and $380 \mathrm{~nm}$ by epi-illumination with a 75 W Xenon lamp. Light was passed through a band pass excitation filter, reflected through a $90^{\circ}$ angle by a dichroic mirror, and passed through the dichroic mirror to a photo-multiplier tube for detection. The emission at $510 \mathrm{~nm}$ was recorded by a Data 6000 digital waveform analyzer and stored on disks. Fluorescence emissions at $510 \mathrm{~nm}$ were subsequently converted with a Basic conversion program (Analogic, Wakefield, MA), downloaded to a PC, and analyzed with GraphPad Prism software (GraphPad Software, San Diego, CA). The ratiometric analysis provided quantitative estimates of $\left[\mathrm{Ca}^{2+}\right]_{i}$ changes. An attempt was made to make an in vitro calibration with EGTA-buffered solutions (ionic strength $150 \mathrm{mM}$ ). Estimation of $\left[\mathrm{Ca}^{2+}\right]_{\mathrm{i}}$ was made from the ratio measurements with the formula $\left[\mathrm{Ca}^{2+}\right]_{\mathrm{i}}=K_{\mathrm{d}} \beta\left(R-R_{\min }\right) /\left(R_{\max }-R\right)$, where $K_{\mathrm{d}}$ is the apparent dissociation constant of Fura-2 $(400 \mathrm{nM}), R$ is the ratio of the fluorescence intensities excited at 360 and $380 \mathrm{~nm}$, $R_{\text {min }}=0.26 \pm 0(n=3)$ is the ratio under $\mathrm{Ca}^{2+}$-free conditions $\left(-\log \left[\mathrm{Ca}^{2+}\right]>9\right) ; R_{\max }=1.8 \pm 0(n=3)$ is the maximum ratio at $\mathrm{Ca}^{2+}$ saturation $\left(-\log \left[\mathrm{Ca}^{2+}\right]=3.5\right)$; and $\beta=5.1 \pm 0.5(n=3)$ is the ratio of $380 \mathrm{~nm}$ fluorescence under minimum and maximum $\left[\mathrm{Ca}^{2+}\right]$ conditions.

\section{Confocal laser scanning microscopy.}

Fluo-3-loaded segments were viewed with a CLSMFLUOVERT system with an inverted microscope (Leica Lasertechnik, Heidelberg, Germany). Intracellular fluorescence was excited with the 488-nm band of an argon-ion laser directed through computer-controlled galvanometer mirrors. Emitted fluorescence passed through a long-pass filter (515 $\mathrm{nm}$ cut-on) and was collected by a photo-multiplier tube. The average number of scans collected per image (time point) was 16. The autofluorescence of $V$. unguiculata, A. thaliana, and $P$. crispum root-hair tips is just visible at a laser power exceeding that routinely used (data not shown). Baseline changes of fluorescence were monitored at 90 -s intervals, usually over a period of $8 \mathrm{~min}$, and root hairs were selected when fluorescence did not change significantly. It was assumed that neither incomplete hydrolysis nor leakage of the dye occurred in such root hairs. The scanning plane of the image was selected so as to include the most homogenous cytosolic fluorescence area at the tip of root hair (cf. Fig. 5A and B). In some experiments, we imaged the length of the root hair and epidermal cells as distinct from the tip. Figures 5A and 6A show light micrographs of the Fluo-3-loaded root-hair tips. When these micrographs are compared with the image, it is apparent that the signal is mainly confined to the cytosolic area and largely excluded from the vacuoles. Some punctate signal is evident
(Figs. 4-6), which is indicative of dye accumulation in small organelles. Although $\left[\mathrm{Ca}^{2+}\right]_{\mathrm{i}}$ can be estimated using in vivo calibrations of Fluo-3-loaded root segments with ionophore additions, this method is fraught with problems due in particular to uneven dye loading when the signal cannot be corrected for by ratio measurements (for discussion see Read et al. 1992). In this paper, we report on increases in Fluo-3 fluorescence as a qualitative indicator of where $\left[\mathrm{Ca}^{2+}\right]_{\mathrm{i}}$ increases occur in the cell. Nod factors or other stock solutions (usually $2 \mu \mathrm{l}$ ) were added to root segments submersed in about $25 \mu \mathrm{l}$ of B \& D solution to allow diffusion of the factor to the root segment. This procedure was used to avoid disturbing the root hairs.

\section{ACKNOWLEDGMENTS}

We are grateful to B. Relić for help in preliminary experiments and we wish to thank S. Jabbouri and F. Talmont for supplying the NodNGR[Ac,S] factors. J. Dénarié generously donated the $R$. meliloti Nod factors. D. Gerber helped with many aspects of this work. We thank T. Phillips and E. Skuza for processing the photographic material. We are grateful to G. Stephenson, I. Newman, and J. Whittington for many helpful discussions. Sponsorship of these studies by Leica Lasertechnik $\mathrm{GmbH}$, Heidelberg, Germany, is gratefully acknowledged. W.J.B. gratefully acknowledges a CRA/La Trobe University Distinguished Visiting Fellowship. Financial assistance was provided by the Erna och Victor Hasselblads Stiftlese, the Fonds National de la Recherche Scientifique (Projects 31-30950.91 and 31-36454.92), the Australian Research Council, the Université de Genève, and La Trobe University.

\section{LITERATURE CITED}

Aeschbacher, R. A., Schiefelbein, J. W., and Benfey, P. N. 1994. The genetic and molecular basis of root development. Annu. Rev. Plant Physiol. Plant Mol. Biol. 45:25-45.

Allen, N. S., Bennett, M. N., Cox, D. N., Shipley, A., Ehrhardt, D. W., and Long, S. R. 1994. Effects of Nod factors on alfalfa root hair $\mathrm{Ca}^{2+}$ and $\mathrm{H}^{+}$currents and on cytoskeleton behaviour. Pages 107-114 in: Advances in Molecular Genetics of Plant-Microbe Interactions, Vol. 3. M. G. Daniels, J. A. Downie, and A. E. Osbourne, eds. Kluwer Academic Pub., Dordrecht, the Netherlands.

Ardourel, M., Demont, N., Debellé, F., Maillet, F., de Billy, F., Promé, J.-C., Dénarié, J., and Truchet, G. 1994. Rhizobium meliloti lipooligosaccharide nodulation factors: Different structural requirements for bacterial entry into target root hair cells and induction of plant symbiotic developmental responses. Plant Cell 6:1357-1374.

Ayling, S. M., Brownlee, C., and Clarkson, D. T. 1994. The cytoplasmic streaming response of tomato root hairs to auxin; observations of cytosolic calcium levels. J. Plant Physiol. 143:184-188.

Brewin, N. J. 1991. Development of the legume root nodule. Annu. Rev. Cell Biol. 7:191-226.

Broughton, W. J., Bohlool, B. B., Shaw, C. H., Bohnert, H. J., and Pankhurst, C. E. 1985. Conserved plasmid/chromosome sequences in fastand slow-growing rhizobia that nodulate the same plant. Arch. Microbiol. 141:14-21.

Broughton, W. J., and Dilworth, M. J. 1971. Control of leghaemoglobin synthesis in snake beans. Biochem. J. 125:1075-1080.

Bush, D. S. 1995. Calcium regulation in plant cells and its role in signalling. Annu. Rev. Plant Physiol. Plant Mol. Biol. 46:95-122.

Clarkson, D. T., Brownlee, C., and Ayling, S. M. 1988. Cytoplasmic calcium measurements in intact higher plant cells: Results from fluorescence ratio imaging of Fura-2. J. Cell Sci. 91:71-80.

Cook, D., Drier, D., Bonnet, D., Howl, M., Non, E., and VandenBosch, K. 1995. Transient induction of a peroxidase gene in Medicago trunculata precedes infection by Rhizobium meliloti. Plant Cell 7:43-55.

Cormack, R. G. H. 1949. The development of root hairs in angiosperms. Bot. Rev. 15:583-612.

Dazzo, F. B., Orgambide, G. G., Philip-Hollongsworth, S., Hollingsworth, R. I., Ninke, K. O., and Salzwedel, J. L. 1996. Modulation of development, growth dynamics, wall crystallinity, and infection sites in white clover root hairs by membrane chitolipooligosaccharides 
from Rhizobium leguminosarum biovar trifolii. J. Bacteriol. 178: 3621-3627.

Dénarié, J., and Cullimore, J. 1993. Lipo-oligosaccharide nodulation factors: A new class of signalling molecules mediating recognition and morphogenesis. Cell 74:951-954.

Dolmetsch, R. E., Lewis, R. S., Goodnow, C. C., and Healy, J. I. 1997. Differential activation of transcription factors induced by $\mathrm{Ca}^{2+}$ response amplitude and duration. Nature 386:855-858.

Ehrhardt, D. W., Atkinson, E. M., and Long, S. R. 1992. Depolarization of alfalfa root hair membrane potential by Rhizobium meliloti Nod factors. Science 256:998-1000.

Ehrhardt, D. W., Wais, R., and Long, S. R. 1996. Calcium spiking in plant root hairs responding to Rhizobium nodulation signals. Cell 85: 673-681.

Fellay, R., Rochepeau, P., Relić, B., and Broughton, W. J. 1995. Signals to and emanating from Rhizobium largely control symbiotic specificity. Pages 199-220 in: Pathogenesis and Host Specificity in Plant Diseases. Histopathological, Biochemical, Genetic and Molecular Bases. Vol. 1. U. S. Singh, R. P. Singh, and K. Kohmoto, eds. Pergamon/Oxford Science, Oxford.

Felle, H. H., Kondorosi, E., Kondorosi, A., and Schultze, M. 1995. Nod signal-induced plasma membrane potential changes in alfalfa root hairs are differentially sensitive to structural modifications of the lipochitooligosaccharide. Plant J. 7:939-947.

Fisher, R. F., and Long, S. R. 1992. Rhizobium-plant signal exchange. Nature 357:655-660.

Gehring, C. A., Irving, H. R., and Parish, R. W. 1990. Effects of auxin and abscisic acid on cytosolic calcium and $\mathrm{pH}$ in plant cells. Proc. Natl. Acad. Sci. USA 87:9645-9649.

Heidstra, R., Geurts, R., Franssen, H., Spaink, H. P., van Kammen, A., and Bisseling, T. 1994. Root hair deformation activity of nodulation factors and their fate in Vicia sativa. Plant Physiol. 105:787-797.

Hiltner, L. 1900. Über die Ursachen, welche die Grösse, Zahl, Stellung und Wirkung der Wurzelknöllchen der Leguminosen bedingen. Arb. Biol. Abt. Land. Forstwirthsch. Kais. Gesundh., Berlin 1:177-222.

Hirsch, A. M. 1992. Developmental biology of legume nodulation. New Phytol. 122:211-237.

Jackson, S. L., and Heath, I. B. 1993. Roles of calcium ions in hyphal tip growth. Microbiol. Rev. 57:367-382.

Journet, E. P., Pichon, M., Dedieu, A., deBilly, F., Truchet, G., and Baker, D. G. 1994. Rhizobium meliloti Nod factors elicit cell-specific transcription of the ENOD12 gene in transgenic alfalfa. Plant J. 6: 241-249.

Kochian, L. V., Shaff, J. E., Kühtreiber, W. M., Jaffe, L. F., and Lucas, W. J. 1992. Use of an extracellular, ion-selective, vibrating microelectrode system for the quantification of $\mathrm{K}^{+}, \mathrm{H}^{+}$, and $\mathrm{Ca}^{2+}$ fluxes in maize roots and maize suspension cells. Planta 188:601-610.

Kurkdjian, A. C. 1995. Role of differentiation of root epidermal cells in Nod factor (from Rhizobium meliloti)-induced root-hair depolarization of Medicago sativa. Plant Physiol. 107:783-790.

Lerouge, P., Roche, P., Faucher, C., Maillet, F., Truchet, G., Promé, J.-C., and Dénarié, J. 1990. Symbiotic host-specificity of Rhizobium meliloti is determined by a sulphated and acylated glucosamine oligosaccharide signal. Nature 344:781-784.

Lewin, A., Cervantes, E., Wong, C.-H., and Broughton, W. J. 1990. nodSU, two new nod genes of the broad host range Rhizobium strain NGR234 encode host-specific nodulation of the tropical tree Leucaena leucocephala. Mol. Plant-Microbe Interact. 3:317-326.

Lewin, A., Rosenberg, C., Meyer z. A., H., Wong, C.-H., Nelson, L., Manen, J.-F., Stanley, J., Dowling, D. N., Dénarié, J., and Broughton, W. J. 1987. Multiple host-specificity loci of the broad host-range Rhizobium sp. NGR234 selected using the widely compatible legume $\mathrm{Vi}$ gna unguiculata. Plant Mol. Biol. 8:447-459.

Mergaert, P., van Montagu, M., Promé, J.-C., and Holsters, M. 1993. Three unusual modifications, a D-arabinosyl, an $N$-methyl, and a carbamoyl group, are present on the Nod factors of Azorhizobium caulinodans strain ORS71. Proc. Natl. Acad. Sci. USA 90:1551-1555.
Mylona, P., Pawlowski, K., and Bisseling, T. 1995. Symbiotic nitrogen fixation. Plant Cell 7:869-885.

Price, N. P. J., Relić, B., Talmont, F., Lewin, A., Promé, D., Pueppke, S. G., Maillet, F., Dénarié, J., Promé, J.-C., and Broughton, W. J. 1992. Broad-host-range Rhizobium species strain NGR234 secretes a family of carbmoylated and fucosylated, nodulation signals that are $O$ acetylated or sulphated. Mol. Microbiol. 6:3575-3584.

Read, N. D., Allan, W. T. G., Knight, H., Knight, M. R., Malho, R., Russell, A., Shacklock, P. S., and Trewavas, A. J. 1992. Imaging and measurement of cytosolic free calcium in plant and fungal cells. J. Microscopy 166:57-86.

Relić, B., Fellay, R., Lewin, A., Perret, X., Price, N. P. J., Rochepeau, P., and Broughton, W. J. 1993a. nod Genes and Nod factors of Rhizobium species NGR234. Pages 183-189 in: New Horizons in Nitrogen Fixation. R. Palacios, J. Mora, and W. E. Newton, eds. Kluwer Academic Pub., Dordrecht, the Netherlands.

Relić, B., Perret, X., Estrada-Garcia, M. T., Kopcinska, J., Golinowski, W., Krishnan, H. B., Pueppke, S. G., and Broughton, W. J. 1994. Nod factors of Rhizobium are a key to the legume door. Mol. Microbiol. 13:171-178.

Relić, B., Staehelin, C., Fellay, R., Jabbouri, S., Boller, T., and Broughton, W. J. 1995. Do Nod-factor levels play a role in host-specificity? Pages 69-75 in: Proc. Eur. Nitrog. Fix. Conf., 1st. G. B. Kiss and G. Endre, eds. Officina Press, Szeged, Hungary.

Relić, B., Talmont, F., Kopcinska, J., Golinowski, W., Promé, J.-C., and Broughton, W. J. 1993b. Biological activity of Rhizobium sp. NGR234 Nod-factors on Macroptilium atropurpureum. Mol. PlantMicrobe Interact. 6:764-774.

Roche, P., Debellé, F., Maillet, F., Lerouge, P., Faucher, C., Truchet, G., Dénarié, J., and Promé, J.-C. 1991. Molecular basis of symbiotic host specificity in Rhizobium meliloti: nodH and nodPQ genes encode sulfation of lipo-oligosaccharide signals. Cell 67:1131-1141.

Rosenberg, C., Boistard, P., Dénarié, J., and Casse-Delbart, F. 1981. Genes controlling early and late functions in symbiosis are located on a megaplasmid in Rhizobium meliloti. Mol. Gen. Genet. 184:326-333.

Schiefelbein, J. W., Shipley, A., and Rowse, P. 1992. Calcium influx at the tip of growing root-hair cells of Arabidopsis thaliana. Planta 187: 455-459.

Schnorf, M., Neuhaus-Url, G., Galli, A., Iida, S., Potrykus, I., and Neuhaus, G. 1991. An improved approach for transformation of plant cells by microinjection: Molecular and genetic analysis. Transgenic Res. 1:23-30.

Spaink, H. P., Sheeley, D. M., van Brussel, A. A. N., Glushka, J., York, W. S., Tak, T., Geiger, O., Kennedy, E. P., Reinhold, V. N., and Lugtenberg, B. J. J. 1991. A novel highly unsaturated fatty acid moiety of lipo-oligosaccharide signals determines host-specificity of Rhizobium. Nature 354:125-130.

Stanley, J., Dowling, D. N., and Broughton, W. J. 1988. Cloning of hemA from Rhizobium sp. NGR234 and symbiotic phenotype of a gene-directed mutant in diverse legume genera. Mol. Gen. Genet. 215:32-37.

Truchet, G., Roche, P., Lerouge, P., Vasse, J., Camut, S., de Billy, F., Promé, J.-C., and Dénarié, J. 1991. Sulphated lipo-oligosaccharide signals of Rhizobium meliloti elicit root nodule organogenesis in alfalfa. Nature 351:670-673.

van Brussel, A. A. N., Bakhuizen, R., van Spronsen, P. C., Spaink, H. P., Tak, T., Lugtenberg, B. J. J., and Kijne, J. W. 1992. Induction of preinfection thread structures in the leguminous host plant by mitogenic lipo-oligosaccharides of Rhizobium. Science 257:70-72.

Vasse, J. M., and Truchet, G. 1984. The Rhizobium-legume symbiosis: Observation of root infection by bright-field microscopy after staining with methylene blue. Planta 161:487-489.

Vincent, J. M. 1974. Root-nodule symbioses with Rhizobium. Pages 265-341 in: The Biology of Nitrogen Fixation. A. Quispel, ed. NorthHolland Pub., Amsterdam.

Yao, P. Y., and Vincent, J. M. 1969. Host-specificity in the root hair "curling factor" of Rhizobium spp. Aust. J. Biol. Sci. 22:413-423. 